\title{
O ENSINO DO EXAME FÍSICO PULMONAR ATRAVÉS DO MÉTODO DA PROBLEMATIZAÇÃO*
}

\author{
Adelia Yaeko Kyosen Nakatani** \\ Emilia Campos de Carvalho*** \\ Maria Márcia Bachion****
}

NAKATANI, A.Y.; CARVALHO, E.C.de; BACHION, M.M. O ensino do exame físico pulmonar através do método de problematização. Rev.latino-am.enfermagem, Ribeirão Preto, v. 8, n. 6, p. 117-123, dezembro 2000.

Realizamos pesquisa-ação na Faculdade de Enfermagem da Universidade Federal de Goiás em 1998, com objetivo de implementar e analisar o ensino de exame físico pulmonar através da problematização. Desenvolvemos as fases do Método do Arco junto a um grupo de alunas do $2^{\circ}$ ano de Graduação em Enfermagem. Durante a fase de hipótese de solução, percebemos a necessidade de várias atividades para a fixação do tema. Na avaliação teórica e psicomotora, constatamos que as alunas tiveram maiores dificuldades na percussão e na palpação. Concluímos ser exeqüivel a aplicação da pedagogia da problematização no ensino do exame físico pulmonar.

UNITERMOS: ensino, enfermagem, exame físico

\section{I - INTRODUÇÃO}

A Coleta de Dados é a primeira fase do Processo de Enfermagem. Segundo FARIAS et al. (1990), é realizada com o objetivo de colher os dados que revelem as respostas do cliente frente a seus problemas de saúde, devendo ser coerente com a estrutura teórica que o enfermeiro e/ou a instituição adotam. É necessário, portanto, que as informações sejam consistentes para o enfermeiro identificar as características definidoras que o levarão ao Diagnóstico de Enfermagem.

Dentre o universo de dados a serem colhidos, estão aqueles provenientes do exame físico que, por sua vez, tem sido objeto de várias pesquisas, configurando um desafio para o ensino de enfermagem.

KOIZUMI (1976) elaborou uma metodologia de ensino do exame físico, utilizando um roteiro para exame. O ensino teórico foi realizado na sala de aula, incluindo exercícios de preenchimento do roteiro. $\mathrm{O}$ ensino prático foi realizado em grupos de dois a quatro alunos incluindo (1) demonstração, pelo docente, do primeiro contato com paciente e do exame físico propriamente dito; (2) execução do exame físico pelo estudante como devolução imediata do método observado; (3) desenvolvimento do exame físico para prestação da assistência integral ao paciente, sendo que, ao final, cada aluno efetuou uma média de 9,7 exames físicos no período de três meses. As considerações finais feitas pela autora sobre esse trabalho, afirmam a eficácia do ensino proposto.

ARAÚJO et al. (1994) desenvolveram o curso "Exame Físico", voltado para Enfermeiros, com duração de 32 horas. As dificuldades apontadas pelos participantes foram a curta duração, a falta de parte prática e de material complementar.

SOUSA \& BARROS (1998), verificando o ensino de exame físico em escolas de Graduação em Enfermagem do município de São Paulo, concluíram que não existe matéria específica para ensinar exame físico, sendo ministrado principalmente na disciplina Fundamentos de Enfermagem. Os fatores dificultadores do ensino do conteúdo foram, principalmente, conhecimento insuficiente em percussão $(46,1 \%)$, ausculta $(43,6 \%)$ e palpação $(35,9 \%)$, relação entre número de docentes e aluno $(30,8 \%)$, insuficientes carga horária e preparo acadêmico dos docentes para o ensino do tema.

\footnotetext{
* Este trabalho contou com auxílio do Programa Institucional de Capacitação Docente (PICDT)

** Doutoranda da área de Enfermagem Fundamental da Escola de Enfermagem de Ribeirão Preto da Universidade de São Paulo e Professor Adjunto I da Faculdade de Enfermagem da Universidade Federal de Goiás. Endereço: Rua: Platina, 135 - Quadra 87 - Lote 2 - Jardim Guanabara - 74675-670 - Goiânia - Goiás - Brasil

*** Professor Titular do Departamento de Enfermagem Geral e Especializada da Escola de Enfermagem de Ribeirão Preto da Universidade de São Paulo

**** Professor Titular da Faculdade de Enfermagem da Universidade Federal de Goiás
} 
OLIVEIRA (1998), ao testar estratégias de ensino na área, evidenciou que os alunos verbalizaram que os recursos de vídeo, com discussão concomitante, foram os que melhor favoreceram o aprendizado sobre exame físico.

Essas pesquisas vêm reforçar a necessidade de se promover condições visando à participação ativa dos alunos na sala de aula, para que a aprendizagem se concretize com maior significado. A educação problematizadora tem sido apontada como ideal para o ensino superior, com grande potencial pedagógico para preparar os profissionais e cidadãos exigidos por uma sociedade que passa por rápidas transformações (BERBEL, 1995).

O esquema do Modelo de Arco, descrito por MAGUEREZ (1970), foi posteriormente reapresentado por DIAZ-BORDENAVE \& PEREIRA (1995), recebendo a seguinte descrição adotada no presente estudo: observação da realidade, identificação dos pontos-chaves, teorização, hipótese de solução e aplicação.

Diante da complexidade do ensino da temática e da importância do enfermeiro dominar o exame físico para possibilitar uma coleta de dados abrangente, de modo a embasar uma assistência segura e confiável, propusemos, na disciplina Metodologia da Assistência de Enfermagem, oferecida aos alunos do $2^{\circ}$ ano de Graduação em Enfermagem, o exame físico pulmonar através da problematização, utilizando o Método do Arco. Esse trabalho tem como objetivo analisar a implementação da proposta de exame físico pulmonar através da Pedagogia da Problematização.

\section{2 - METODOLOGIA}

O trabalho foi realizado na Faculdade de Enfermagem da Universidade Federal de Goiás através de pesquisa-ação. A população estudada era composta de alunas do $2^{\circ}$ ano matriculadas na disciplina Metodologia da Assistência de Enfermagem no ano de 1998. Inicialmente, elaboramos os planos de aula para unidade em seguida, selecionamos para a amostra 19 alunas que haviam cursado o primeiro ano na mesma faculdade, presentes no primeiro dia de aula, livre de pendências em disciplinas no ano anterior. As alunas concordaram em participar do estudo após esclarecimento do objetivo, garantia do sigilo dos dados e sua utilização somente para trabalhos técnico-científicos, atendendo à Resolução 196/96 (BRASIL, 1996). Durante a implementação do plano de aula, contamos com auxílio de uma monitora e das professoras responsáveis pela disciplina.
Para a coleta de dados utilizamos a observação participante, o diário de campo, os relatórios das alunas e a avaliação do alcance dos objetivos traçados para a unidade. Os resultados foram apresentados através de freqüência simples e das expressões mais significativas de cada categoria.

\section{3 - APRESENTAÇÃO DA IMPLEMENTAÇÃO DO PLANO DA UNIDADE}

\subsection{Observação da realidade e levantamento dos pontos-chaves:}

Para a observação da realidade sobre exame pulmonar, distribuímos um instrumento tipo chek-list para as alunas, divididas em grupos de três componentes. Solicitamos que, diante do instrumento, fosse simulado um exame, a fim de detectar o nível de conhecimento de cada uma em relação à temática.

Estabelecemos, no instrumento, uma escala do tipo likert com três pontos a saber: não domina, significou que elas não sabiam como identificar determinado dado; domínio parcial, quer dizer, identificam mas não sabem descrever nem examinar, não têm certeza e domina equivale ao fato delas saberem realizar a coleta de determinada informação.

A realidade observada indicou que a maioria dos itens de inspeção variou de $50 \%$ a $83,3 \%$ para a categoria domina parcialmente; já a percussão não era dominada por $83,3 \%$ dos grupos, a ausculta pulmonar ficou entre as categorias não domina e domina parcialmente, numa proporção de $66,7 \%$ e $33,3 \%$, respectivamente. Os itens que $100 \%$ das alunas não dominaram foram: retração dos espaços intercostais, expansão torácica posterior e anterior de base, expansão torácica anterior de ápice e verificação de frêmito tóraco vocal.

Prosseguindo no Modelo do Arco, entregamos o roteiro da aula, incluindo o assunto, os objetivos, o tempo previsto, as estratégias utilizadas para o ensino e a avaliação do conteúdo e solicitamos que esses dados fossem avaliados. Em seguida, os objetivos específicos da unidade foram reavaliados em conjunto com as alunas.

No final da aula, foi entregue um instrumento de avaliação e solicitado que o preenchimento fosse realizado com base no roteiro da aula. Este instrumento possibilitou a identificação dos pontos facilitadores e dos dificultadores da aula. A seguir destacamos os mais significativos:

Fatores dificultadores:

desconhecimento de anatomia e fisiologia;

ainda não estudamos o assunto detalhadamente; 
não tínhamos noção nenhuma de como fazer tal coisa;

não conhecíamos como examinar o tórax.

Os facilitadores:

foi muito boa...;

a aula nos mostrou a importância de rever

a matéria que já havia sido estudada, mas esquecida;

tenho muito que estudar pois não sei como agir na realização de um exame físico, não sabia nada sobre inspeção, posição, palpação.

Fica evidente que o foco de dificuldade das alunas nesta fase é em relação ao conteúdo. Partimos da percepção de que as dificuldades promovem a motivação necessária para a abordagem do tema. Acreditamos que essa auto-avaliação pode auxiliar no sentido de motivar as alunas para as próximas atividades sobre o tema, ou seja, leitura de um texto e teorização do assunto.

\subsection{Teorização:}

Após a primeira etapa, sugerimos, como tarefa, que as alunas fizessem a leitura do texto de BATES, B. et al. Pulmão. In: .... Propedêutica médica. 6.ed. Rio de Janeiro: Guanabara Koogan, 1995, Cap. 8, p. 229-57, e fornecemos uma lista de termos técnicos, incluindo aí os nomes dos principais sinais e sintomas do sistema respiratório para que as alunas procurassem esses termos em um dicionário (BATES et al., 1995).

$\mathrm{Na}$ aula seguinte, antes de dar continuidade às atividades de teorização, perguntamos quantos haviam lido o texto. Apenas uma aluna não tinha lido. Quanto à avaliação do seu conteúdo, a maioria respondeu que se tratava de um assunto bastante difícil de compreender em uma primeira aproximação.

Prosseguindo, a aula foi construída novamente com a participação ativa do grupo, alternando estratégias de exposição dialogada com demonstração prática e exercício em sala de aula. Buscamos relacionar o tema a conhecimentos de anatomia, fisiologia com base nos dados fornecidos pela observação da realidade. Percebemos que as fases anteriores auxiliaram na dinamização da aula, pois houve vários questionamentos elaborados a partir das atividades de observação da realidade e do levantamento dos pontos-chaves.

Em seguida, expusemos uma fita "cassete" com diferentes tipos de sons pulmonares.

Da mesma forma que anteriormente, buscamos identificar, na avaliação, os pontos facilitadores e os dificultadores.

Os principais pontos facilitadores foram:

...apesar de ser um assunto novo para a turma, a professora foi muito clara e objetiva ao expô-lo;

... a aula com auxílio das alunas para demonstração, facilitaram o entendimento; a professora esteve presente o tempo todo nos auxiliando e ensinando as técnicas de exame.

Os principais pontos dificultadores foram: eu tive dificuldades na aula, pois eu não tive possibilidades de fazer leitura do texto antecipadamente;

tive dificuldades na palpação, na percussão e para diferenciar os sons produzidos; houve pouco tempo para as alunas treinarem inspeção, palpação, percussão e ausculta.

Destacamos, aí, a percepção em relação à clareza e a objetividade da explicação por parte das professoras. As alunas situaram-se como participantes ativas do processo de ensino-aprendizagem e avaliaram de forma favorável a prática concomitante à teoria, o que vem reforçar a convicção de que aprender é uma atividade que acontece e deve ser realizada pela aluna (DIAZBORDENAVE \& PEREIRA, 1995). Portanto, cabe ao professor selecionar estratégias que possibilitem essas participações.

Levar alunos acostumados à passividade pedagógica e ao individualismo - favorecidos por aulas expositivas, nas quais o ensino é centrado na figura do professor - para estratégias que permitam a interação de conhecimentos, a troca entre os elementos do grupo e a participação ativa é um desafio para todos nós, docentes, pois a nossa tendência é ensinar de um modo que reforça nos alunos uma atitude de expectadores.

As dificuldades citadas nessa aula foram principalmente em relação às habilidades necessárias ao exame físico. No entanto, essas habilidades só serão adquiridas à medida que cada uma se responsabilizar por esta aquisição, cabendo ao professor proporcionar oportunidades de aprendizagem.

As avaliações em relação a essa estratégia demostram o quanto é difícil o primeiro contato com a informação. Como a aprendizagem é um processo ativo, o desempenho do professor não poderá ser considerado com o único determinante. De acordo com ABREU \& MASETTO (1987, p. 11),

o papel do professor não é ensinar, mas ajudar o aluno aprender; não é transmitir informações, mas criar condições para que aluno adquira informações; não é fazer brilhantes preleções para divulgar cultura, mas organizar estratégias para que o aluno conheça a cultura existente e crie cultura.

Acreditamos que, quanto mais diversificadas forem as formas de ensinar sobre um mesmo assunto, 
mais será favorecida a aprendizagem, pois estará sendo promovido o desenvolvimento de várias capacidades das alunas.

\subsection{Hipótese de solução}

Para a hipótese de solução, o grupo treinou o exame físico com o auxílio da monitora e, posteriormente, dirigiu-se para o hospital para realizar entrevista e exame físico em clientes hospitalizados escolhidos aleatoriamente.

$\mathrm{Na}$ avaliação da estratégia da aplicação da entrevista e exame pulmonar, foram destacados, por parte das alunas, os seguintes pontos dificultadores:

tive dúvidas na ausculta, mas é questão de mais treino com ruídos pulmonares;

frustrante desde a escolha do paciente até constrangimento causado pela falta de habilidade;

fiquei sinceramente frustrada com o que vivi. Falta-nos um acompanhamento mais específico e personalizado, falta-nos segurança...

Os pontos facilitadores apontados foram: tivemos sorte em encontrar alguém que estivesse com problemas de pulmão; adorei realizar o trabalho de campo, eu sinto com mais responsabilidade ao executar tal procedimento em um cliente, é diferente de realizar em um colega de sala.

A abordagem ao cliente foi referida tanto como facilitador como dificultador da realização da atividade. Verificamos que, em contato com os clientes, as alunas conseguiram perceber com clareza as dificuldades, principalmente as relacionadas à ausculta e à percussão. Algumas apontaram constrangimento, medo e insegurança diante do cliente, além de reclamarem a falta de acompanhamento do professor ou da monitora durante a execução dessas atividades.

As dificuldades técnicas serão superadas à medida que houver treinamento das habilidades auditivas, para ausculta dos sons pulmonares, e auditiva e motora, empregadas na percussão pulmonar. As primeiras vezes em que essas técnicas são executadas, há a necessidade de um ambiente livre de barulhos, o que muitas vezes não se consegue em uma enfermaria, dificultando a ausculta dos sons produzidos pelo estetoscópio ou pelo golpeamento dos espaços intercostais.

Verificamos que a falta de acompanhamento de um professor/orientador foi apontada por um grande número de participantes. A presença do professor pode facilitar o desempenho da tarefa sem que a autonomia da aluna em exercer as novas atividades seja cerceada. A dependência do apoio de um professor pode, da mesma forma, prejudicar a formação das alunas, tornando-as inseguras e dependentes.

O trabalho em duplas foi avaliado positivamente, o que vem confirmar o posicionamento de ABREU \& MASETTO (1987) em relação a essa atividade. No entanto, as estratégias de ensino devem ser diversificadas, a fim de favorecer as particularidades individuais, pois trabalhar em grupo, incluindo pessoas com diferentes níveis de desempenho e posturas divergentes, pode dificultar a aprendizagem.

Propusemos, ainda, uma aula de revisão, com objetivo de esclarecer dúvidas. Essa aula desenvolveuse em forma de perguntas e respostas, procurando seguir os itens de avaliação de exame físico. As alunas participaram, respondendo e demonstrando as questões e situações propostas, até que todas essas questões fossem corrigidas e/ou respondidas pelo professor, caso houvesse necessidade.

$\mathrm{Na}$ avaliação da aula, foram destacados os seguintes pontos facilitadores:

a aula foi importante e ajudou muito no esclarecimento de dúvidas e reforçou os pontos principais para realização do exame fisico;

as etapas foram bem detalhadas e as dúvidas, resolvidas.

Os pontos dificultadores apontados foram: realmente, o que eu ainda sinto insegurança é na realização de percussão, pois não consigo com clareza diferenciar os sons, mas o que me resta é praticar.. e educar meu ouvido.

As dúvidas decorriam da dificuldade de diferenciar os sons na percussão, o que é aceitável, pois essa técnica requer a aplicação de golpes indiretos sobre a superfície torácica e a produção de sons com qualidade para permitir sua diferenciação, necessitando, portanto, de muito treino para a aquisição de tais habilidades.

Percebemos que a ausculta pulmonar, que era considerada como dificuldade na fase anterior, não foi mais citada, permanecendo, todavia, como dificuldade, a percussão pulmonar.

Após uma aula de reforço, realizamos uma avaliação formal da aprendizagem de exame físico pulmonar no laboratório, sendo que as alunas examinaram-se entre si. Para possibilitar a avaliação da aprendizagem de todos os itens, foi utilizada a estratégia de prova prática e teórica, na qual a aluna deveria proceder a um exame físico, seguido de registro desse exame.

Visando evitar a subjetividade nas avaliações de cada item do exame físico, foram elaborados critérios gerais orientadores, com escores de 5 a 1 , no intervalo domina-não domina. O Quadro 1 apresenta os resultados 
da avaliação em $100 \%$ da amostra.

Não houve dificuldades para a inspeção, exceto no item 4 , no qual tiveram a pontuação baixa devido às alunas não terem registrado nenhuma das observações realizadas. Acreditamos que isto se deva ao "hábito de não reportar o normal".

Verificamos que as maiores dificuldades no exame pulmonar recaíram sobre a palpação e a percussão.

Quadro 1 - Distribuição das alunas participantes do estudo, segundo escore obtido em cada item de avaliação do exame físico pulmonar. Goiânia, 1998

\begin{tabular}{|c|c|c|c|c|c|c|c|c|c|c|c|c|c|c|c|c|c|c|c|c|}
\hline \begin{tabular}{|l} 
Sujeitos \\
Itens de avaliação
\end{tabular} & $\mathrm{A}$ & $\mathrm{B}$ & $\mathrm{C}$ & $\mathrm{D}$ & $E$ & $\mathrm{~F}$ & $\mathrm{G}$ & $\mathrm{H}$ & I & $\mathrm{J}$ & $\mathrm{L}$ & $\mathrm{M}$ & $\mathrm{N}$ & 0 & $\mathrm{P}$ & $\mathrm{Q}$ & $\mathrm{R}$ & $\mathrm{S}$ & $\mathrm{T}$ & TOTAL \\
\hline 1) Posicionar para exame & 4 & 3 & 5 & 5 & 4 & 5 & 5 & 5 & 5 & 4 & 3 & 4 & 5 & 4 & 4 & 5 & 5 & 4 & 5 & 84 \\
\hline $\begin{array}{l}\text { 2) Reconhecer as linhas } \\
\text { imaginárias torácicas anterior } \\
\text { e posterior eo } \hat{A} \text { ngulo de Louis }\end{array}$ & 5 & 4 & 5 & 5 & 5 & 4 & 4 & 5 & 4 & 3 & 4 & 5 & 5 & 5 & 5 & 5 & 5 & 5 & 5 & 87 \\
\hline \multicolumn{21}{|l|}{$\begin{array}{l}\text { Fazer inspeção: detectar e } \\
\text { descrever: }\end{array}$} \\
\hline 3) Lesões de pele & 4 & 5 & 1 & 5 & 4 & 5 & 5 & 4 & 5 & 3 & 5 & 5 & 5 & 5 & 5 & 1 & 5 & 5 & 5 & 81 \\
\hline 4) Deformidades estruturais & 1 & 4 & 4 & 5 & 1 & 5 & 5 & 3 & 5 & 2 & 5 & 1 & 1 & 1 & 5 & 1 & 1 & 5 & 5 & 60 \\
\hline $\begin{array}{l}\text { 5) Amplitude, frequiência e } \\
\text { ritmo dos movimentos e } \\
\text { dificuldade respiratónia }\end{array}$ & 1 & 4 & 2 & 4 & 2 & 4 & 2 & 3 & 3 & 3 & 2 & 5 & 2 & 1 & 1 & 4 & 4 & 5 & 3 & 55 \\
\hline \multicolumn{21}{|l|}{$\begin{array}{l}\text { Fazer palpação superficial nas } \\
\text { faces anterior, lateral e } \\
\text { posterior: }\end{array}$} \\
\hline $\begin{array}{l}\text { 6) Avaliar expansão torácica de } \\
\text { ápice e de base do tórax } \\
\text { posterior }\end{array}$ & 1 & 3 & 2 & 4 & 3 & 2 & 1 & 4 & 1 & 4 & 4 & 4 & 3 & 1 & 2 & 3 & 2 & 1 & 3 & 79 \\
\hline $\begin{array}{l}\text { 7) Avaliar exparsão do carmpo } \\
\text { superior e de base no tórax } \\
\text { anterior }\end{array}$ & 1 & 3 & 2 & 4 & 3 & 2 & 1 & 4 & 1 & 4 & 4 & 4 & 3 & 1 & 2 & 3 & 2 & 1 & 3 & 48 \\
\hline $\begin{array}{l}\text { 8) Detectar e descrever o } \\
\text { frêrito tátil do tórax anterior } \\
\text { e posterior }\end{array}$ & 1 & 5 & 4 & 4 & 2 & 4 & 5 & 3 & 5 & 3 & 5 & 4 & 3 & 3 & 3 & 4 & 1 & 4 & 4 & 67 \\
\hline \multicolumn{21}{|l|}{ Fazer percusão } \\
\hline $\begin{array}{l}\text { 9) Percutiro tórax, detectando } \\
\text { e descrevendo os sons } \\
\text { encontrados no tórax anterior } \\
\text { e posterior }\end{array}$ & 3 & 3 & 3 & 3 & 3 & 2 & 4 & 3 & 4 & 3 & 4 & 3 & 3 & 3 & 2 & 4 & 3 & 5 & 3 & 61 \\
\hline $\begin{array}{l}\text { 10) Identificar a descida } \\
\text { inspiratória (incursão } \\
\text { diafragmática) }\end{array}$ & 1 & 2 & 1 & 2 & 1 & 1 & 1 & 1 & 1 & 3 & 1 & 1 & 3 & 3 & 1 & 3 & 3 & 1 & 1 & 31 \\
\hline \multicolumn{21}{|l|}{ Fazer ausculta } \\
\hline $\begin{array}{l}\text { 11) Auscultar os pulmões, } \\
\text { identificando e descrevendo os } \\
\text { sons encontrados, fisiológicos } \\
\text { ou não do tórax anterior e } \\
\text { posterior }\end{array}$ & 5 & 3 & 3 & 3 & 4 & 4 & 2 & 4 & 5 & 4 & 5 & 4 & 3 & 2 & 4 & 3 & 3 & 4 & 4 & 69 \\
\hline
\end{tabular}


A palpação anterior da expansão torácica foi um procedimento aparentemente não valorizado pelas alunas, já que se trata de técnica semelhante àquela realizada no tórax posterior, na qual os escores de desempenho foram melhores. Outra dificuldade pode ser atribuída ao pudor das alunas em tocar a colega em partes mais íntimas.

Na percussão, além da dificuldade técnica, que compromete a qualidade dos sons produzidos, um número grande de alunas (12) esqueceu de realizar o exame de identificação da descida inspiratória (item 10). É possível que, neste último aspecto, não tenha havido reforço suficiente.

O grupo teve problemas em identificar os sons na ausculta pulmonar, porém em proporção menor que na palpação e na percussão. Nesta fase, ainda foi difícil para as alunas diferenciarem os sons e seus registros.

\subsection{Aplicação}

A fase de aplicação do Método do Arco foi realizada durante o período de atividades práticas, no qual as alunas tiveram oportunidades de realizar nove experiências, sempre que possível com acompanhamento. A média de proporção professor/aluno no campo de atividades práticas foi um para oito (1:8). Quando nós acompanhávamos as alunas, umas nos recebiam de modo positivo enquanto outras o faziam de forma oposta. No final da terceira semana, a prática dessa fase apresentou maior desenvoltura, rapidez, segurança e exatidão, além de independência de algum acompanhamento.

\section{4 - CONCLUSÃO}

Estabelecemos como proposta de estudo, analisar a implementação do ensino de exame físico pulmonar através da Pedagogia da Problematização. Para concretizar a proposta, percorremos os seguintes passos através do Método do Arco:

- observação da realidade, realizando auto-avaliação dos conhecimentos prévios das alunas sobre a temática; - identificação dos pontos-chaves, traçando, em conjunto com as alunas, os objetivos da aula;

- teorização, solicitando a leitura prévia de um texto e uma aula expositiva dialogada, com demonstração e exercícios concomitantes;

- hipótese de solução, agendando treinamentos no Laboratório de Enfermagem, sob supervisão da monitora e aulas de esclarecimento de dúvidas;

- aplicação, realizando atividades práticas, em instituição hospitalar.

Quanto à avaliação das atividades, destacamos como dificuldade, principalmente, a falta de conhecimentos prévios sobre o conteúdo abordado e como facilidade o desenvolvimento da autocrítica.

As alunas destacaram, na avaliação da teorização, dificuldades relativas à primeira aproximação com o tema e à identificação dos sons e, facilidades, a clareza, a objetividade e as atividades interativas e participativas.

$\mathrm{Na}$ fase de hipótese de solução, identificamos como dificuldades, para algumas alunas, a solução de todas as dúvidas e, como facilidades, o esclarecimento de dúvidas e a constatação de que sabiam examinar.

Durante a fase de aplicação, as dificuldades de examinar foram gradativamente vencidas ao longo de nove experiências.

Concluímos que a aplicação da Pedagogia da Problematização no ensino de exame físico é exequível, tendo como principal contribuição a avaliação do processo de aprendizado, no qual professor e alunas conseguiram identificar pontualmente as dificuldades/ facilidades.

\section{TEACHING PHYSICAL PULMONARY EXAMINATION THROUGH THE PROBLEM-BASED METHOD}

Action-research was accomplished at the Federal University of Goiás College of Nursing in 1998 aiming at implementing and analyzing the teaching resources of physical pulmonary examination through the problem-based method. The Arch Method Phases were developed with sophomores in the undergraduate Nursing Course. During the Conclusion Hypothesis phase, the need of various activities in order to fix the theme was observed. In the theoretical and psycho-motor evaluation, we verified that the students had more difficulty in performing percussion and palpitation. It was concluded that the application of the problembased pedagogy in physical examination was feasible.

KEY WORDS: teaching, nursing, physical examination

\section{LA ENSENÃNZA DEL EXAMEN FÍSICO DE LOS PULMONES A TRAVÉS DEL MÉTODO DE LA PROBLEMATIZACIÓN}


examen físico de los pulmones a través de la problematización. Desarrollamos las fases del Método del “Arco” junto con los estudiantes del segundo año de Pregrado en Enfermería. Resaltamos que durante la fase de hipótesis de solución percibimos la necesidad de varias actividades para entender el tema. En la evaluación teórica y psicomotora constatamos que los alumnos tuvieron mayor dificultad en la percusión e palpación. Concluimos que es posible la aplicación de la pedagogía de la problematización en la enseñanza del examen físico.

TÉRMINOS CLAVES: enseñanza, enfermería, examen físico

\section{5 - REFERÊNCIAS BIBLIOGRÁFICAS}

01. ABREU, M.C. de; MASETTO, M.T. O professor universitário em aula: prática e princípios teóricos. 6. ed. São Paulo: MG Ed. Associados, 1987. 130p.

02. ARAúJO, T.L. et al. A coleta de dados em enfermagem: relato de uma experiência em ensino. Rev. Esc. Enfermagem USP, v. 28, n. 1, p. 59-69, abr. 1994.

03. BERBEL, N.A.N. Pedagogia da problematização: uma alternativa metodológica apropriada para o ensino superior. Semina: Ci. Soc. Hum., v. 16, n. 2, p. 9-19, out. 1995. Edição Especial.

04. BRASIL. Conselho Nacional de Saúde. Resolução $n^{\circ} 196 / 96$ sobre pesquisa envolvendo seres humanos. Bioética, v. 4, n. 2, p. 15-25, 1996.

05. BATES, B.; BICKLEY, L.S.; HOEKELMAN, R.A. Pulmão. In: BATES, B.; BICKLEY, L.S.; HOEKELMAN, R. A. Propedêutica médica. 6. ed. Rio de Janeiro: Guanabara Koogan, 1995. Cap. 8, p. 229-57
06. DIAZ-BORDENAVE, J.D.; PEREIRA, A.M. Estratégias de ensino - aprendizagem. 16. ed. Petrópolis: Vozes, 1995. $316 \mathrm{p}$.

07. FARIAS, J.N. et al. Diagnóstico de enfermagem: uma abordagem conceitual e prática. João Pessoa: Santa Marta, 1990. 160p.

08. KOIZUMI, M.S. Exame físico em pacientes agudos graves: uma experiência de ensino. Enf. Novas Dimens., v. 2, n. 5, p. 284-289, 1976.

09. MAGUEREZ, C. Elementos para uma pedagogia de massa na assistência técnica agrícola. Campinas, 1970. (Relatório apresentado à Coordenadoria da Assistência Integral da Secretaria de São Paulo /mimeo/).

10. OLIVEIRA, E.R.A. O ensino do exame físico por diferentes estratégias. Ribeirão Preto, 1998. 289p. Tese (Doutorado) - Escola de Enfermagem de Ribeirão Preto, Universidade de São Paulo.

11 - SOUSA V. D.; BARROS, A.L.B.L. de. O ensino do exame físico em escolas de graduação em enfermagem do município de São Paulo. Rev. Latino-am.Enfermagem, Ribeirão Preto, v. 6, n. 3, p. 11-22, jul. 1998. 